\title{
FUNGSI SASTRA LISAN “TANDUK” MASYARAKAT GENAHARJO KABUPATEN TUBAN BAGI MASYARAKAT PENDUKUNGNYA
}

\author{
Suantoko \\ FKIP Universitas PGRI Ronggolawe Tuban \\ Pos-el: stsuantoko109@gmail.com \\ DOI: http://dx.doi.org/10.17509/bs_jpbsp.v16i2.4486
}

\begin{abstract}
Abstrak
Penelitian ini betujuan untuk mengkaji fungsi sastra lisan tanduk bagi masyarakat pendukungnya. Dalam hal ini, masyarakat yang dimaksud adalah masyarakat Genaharjo Kabupaten Tuban. Melalui pemanfaatan teori fungsi Alan Dundes dan William R. Bascom, dapat dipahami bahwa sastra lisan tanduk memiliki fungsi yang menitikberatkan sebagai ajaran dan saling tergantung di antara masyarakat yang menekankan manfaat kepraktisan. Fungsi sastra lisan tanduk yaitu fungsi dakwah, fungsi solidaritas sosial dan penangkal individualisme, dan fungsi pendidikan dalam rangka sosialisasi nilai-nilai. Keseluruhan fungsi tersebut membentuk jati diri dalam rangka membangun keharmonisan dalam kehidupan bermasyarakat.
\end{abstract}

Kata kunci: fungsi, masyarakat Genaharjo, sastra lisan tanduk

\begin{abstract}
This study aims to investigate the function of "tanduk" oral literature for its society. In this case, the people in question are society Genaharjo of Tuban district. Through the use of the theory of functions Alan Dundes and William R. Bascom, it is understood that the "tanduk" has a function of oral literature that focuses as the teaching and interdependence among societies that emphasize the benefits of practicality. "Tanduk" oral literature function is the function of propaganda, the function of social solidarity and an antidote to individualism, and the function of education in the socialization of values. The overall function of shaping identity in order to establish harmony in social life.
\end{abstract}

Keywords: function, Genaharjo society, tanduk oral literature

\section{PENDAHULUAN}

Sastra lisan tandukiyang berkembang di Desa Genaharjo sebagai produk budaya masyarakat, memiliki ciri yang sama dengan sastra lisan yang berkembang di Indonesia dari segi bentuk, makna dan fungsi. Ketiga hal tersebut, menarik untuk dikaji dalam rangka menemukan keunikan sastra lisan yang berkembang dalam masyarakat Genaharjo Kabupaten Tuban. Keunikan tersebut, memicu adanya sebuah pertanyaan besar mengenai eksistensi masyarakat setempat untuk terus-menerus mempertahankan produk budayanya.
Sastra lisan tanduk merupakan bentuk sastra lisan yang ditampilkan pada saat kenduren (dalam masyarakat penelitian dinamakan kepungan). Oleh karena itu, sastra lisan yang berkembang pada masyarakat Genaharjo merupakan bentuk sastra lisan yang wajib ditampilkan dalam kenduren atau hajatan. Bahkan, masyarakat setempat menganggap bahwa sebelum dibacakan tanduk, kenduren atau hajatan tersebut belum dapat dikatakan sah.

Penampilan tanduk dibawakan oleh tukang tanduk yaitu modin, tokoh masyarakat atau sesepuh dusun. Penampilannya pun tidak tentu, tergantung 
ada atau tidak kepungan, baik di rumah atau di tempat-tempat yang disakralkan, seperti: pepunden, sendang, pemakaman, dan sumur. Selain itu, pengamatan di lapangan penelitian bahwa sebelum kepungan dilaksanakan, pemangku hajat biasanya mengundang tetangga atau sanak saudara. Biasanya modin atau tukang tanduk didulukan, karena pelaksanaan hajatan bergantung pada kesiapan modin atau tukang tanduk untuk mengikrarkan hajat.

Para tetangga atau sanak saudara yang diundang memberikan tanggapan yang positif pada saat tanduk dibacakan. Para tamu yang diundang sudah mengenali kapan harus memberikan bunyi pengimbuh, karena tukang tanduk menggunakan ungkapan-ungkapan bahasa Jawa yang sudah dikenal oleh masyarakat agar terjadi interaksi. Sesuai dengan pendapat Luxemburg, dkk.(1992:120), bahwa juru bicara utama, si pencerita atau tukang dongeng berinteraksi dengan audien atau penonton untuk menjalin keakraban. Begitu juga dalam pelaksanaan kenduren yang dipimpin oleh tukang tanduk.

Sebagai bagian dari folklor, sastra lisan tanduk yang dituturkan tukang tanduk merupakan salah satu sastra lisan yang mirip syair berbahasa Jawa. Tukang tanduk memilih diksi yang unik dan khas agar menarik saat ditampilkan. Hal inilah yang memunculkan keingintahuan untuk menemukan fungsi dari tanduk yang ditampilkan, sebagaimana fungsi tradisi lisan lainnya yang ada di Nusantara.

Sastra lisan tanduk penting dikaji karena beberapa alasan. Pertama, sastra lisan tanduk terus ada di tengah kehidupan masayarakat Genaharjo. Kedua, sastra lisan tersebut mampu mengikat tali persaudaraan antaranggota keluarga dan tetangga. Hal ini dapat dibuktikan, bahwa setelah terjadi peristiwa ritual budaya yang menampilkan sastra lisan tanduk, masyarakat Genaharjo masih ajek melakukan tradisi ater-ateri. Ketiga, sastra lisan tanduk menyampaikan kebenaran yang diyakini oleh masyarakat Genaharjo sebagai produk budaya lisan.
Amir (2013:19) mengungkapkan bahwa alasan pertama, sastra lisan ada dan terus hidup di tengah masyarakat sebagai produk budaya lisan. Kedua, dari sudut pandang folklor, sastra lisan dapat dilihat dari dua fungsi, (1) sastra lisan berfungsi untuk membangun dan mengikat rasa persatuan kelompok; (2) sastra lisan menyimpan kearifan lokal. Ketiga, memperlihatkan hubungan antara kebudayaan dengan kebudayaan lain. Keempat, sastra lisan dapat mewakili bangsa untuk bersanding dengan sastra lisan dari negara lain.

Berdasarkan data di lapangan tersebut, sastra lisan tanduk sangat menarik apabila dikaji dari aspek fungsi sastra lisan. Pengajian fungsi sastra lisan didasarkan pada teori fungsi sastra lisan hasil perpaduan teori Alan Dundes dan William R. Bascom (Sudikan, 2014:151). Dua teori tersebut saling melengkapi dalam penelitian folklor terutama penelitian sastra lisan. Pemanfaatan dua teori fungsi tersebut diharapkan mampu menggali fungsi-fungsi sastra lisan tanduk bagi masyarakat pendukungnya. Atas dasar uraian tersebut, perlu dilakukan penelitian yang bertujuan untuk memahami fungsi sastra lisan tanduk masyarakat Genaharjo Kabupaten Tuban bagi masyarakat pendukungnya.

\section{METODE PENELITIAN}

Penelitian ini dirancang dalam bentuk penelitian kualitatif. Penelitian tersebut dibangun atas dasar data di lapangan yang dikembangkan berdasarkan tujuan penelitian. Data utama berupa teks tanduk yang diperoleh dari penampilan sastra lisan tanduk.Selain itu, data utama diperoleh melalui wawancara para partisipan. Jenis data dalam penelitian ini adalah data kualitatif. Data yang dimaksud adalah data yang tidak bisa di ukur atau dinilai dengan angka secara langsung (Prastowo, 2010:3; Bungin, 2003:64; Ratna 2010:509). Data dalam penelitian kualitatif bukanlah berdasarkan atas tabel angka-angka hasil pengukuran atau penilaian secara langsung yang mana dianalisis secara statistik. 
Penentuan informan menggunakan konsep Spradley (1997:61) dan konsep Danandjaja (1994:28), prinsipnya menghendaki, seorang informan itu paham terhadap budaya aslinya ${ }^{\text {iii }}$. Ada beberapa kriteria dalam penentuan informan menurut Spradley, yaitu (1) enkulturasi penuh, (2) keterlibatan lansung, (3) suasana budaya yang tidak dikenal,(4) cukup waktu, (5) non analitik. Kriteria yang lain yaitu pewaris aktif (active bearer) dan pewaris pasif (passive bearer). Selain konsep tersebut, penentuan informan didukung oleh konsep Endraswara (2006:57) dan Sudikan (2001:91), penentuan informan kunci harus orang yang bersangkutan memiliki pengetahuan luas mengenai permasalahan yang diteliti ${ }^{\text {iv }}$.

Pengumpulan data menggunakan beberapa teknik. Salah satunya mengacu pada metode etnografi Spradley (1997:63) The Development Research of Secuency, seperti; teknik participant observation dan indepth interview.Fontana dan Frey atau The Open Ended or Ethnographic Interview" (Adler dan Adler, dalam Endraswara, 2006:208).Kedua teknik tersebut merupakan teknik pengumpulan data melalui observasi alamiah dan wawancara mendalam.Kedua teknik ini berpegang teguh pada konsep Spradley (1997:106) bahwa peneliti berusaha menyimpan pembicaraan informan, membuat penjelasan berulang, menegaskan pembicaraan informan, dan tidak menanyakan makna tetapi gunanya. Di samping itu, menggunakan teknik dokumen, sebagaimana dikemukakan oleh Ratna (2010:234), bahwa teknik dokumen yang dimaksud adalah dokumen yang menunjuk pada masa lampau, dengan fungsi utama sebagai catatan atau bukti peristiwa, aktivitas, dann kejadian tertentu.

Analisis data dalam penelitian ini dilakukan melalui beberapa tahap.Tahapan dalam analisis data penelitian ini, tidak ubahnya dengan tahapan dalam analisis data penelitian kualitatif. Menurut Sudikan (2014:136), tahapan tersebut meliputi: open coding, axial coding, dan selective coding untuk menghasilkan simpulan yang diangkat menjadi general design.

\section{HASIL PENELITIAN DAN PEMBAHASAN}

\section{Fungsi Sastra Lisan Tanduk Masyarakat Genaharjo Kabupaten Tuban}

Penelitian ini menggunakan dua teori fungsi yaitu teori fungsi William R. Bascom dan Alan Dundes.Dua teori tersebut saling melengkapi dalam penelitian folklor terutama penelitian sastra lisan. Pemanfaatan dua teori fungsi tersebut diharapkan mampu menggali fungsi-fungsi sastra lisan tanduk bagi masyarakat pendukungnya $^{\mathrm{V}}($ Sudikan, 2014:151).

Menurut William R. Bascom (1965); Alan Dundes (1965), sebagaimana dikutip Sudikan (2014:151) sastra lisan dan sebagian lisan mempunyai empat fungsi: (1) sebagai sebuah bentuk hiburan, (2) sebagai alat pengesahan pranata-pranata sosial dan lembaga kebudayaan, (3) sebagai alat pendidikan anak, dan (4) sebagai alat pemaksa dan alat pengawas agar normanorma masyarakat akan selalu dipatuhi anggota kolektifnya.

Fungsi yang sama dikemukakan oleh Danandjaja (1994:81), bahwa sastra lisan pada umumnya berfungsi sebagai 1) alat pendidikan anggota masyarakat; 2) sebagai alat penebal perasaan solidaritas kolektif; 3) sebagai alat yang memungkinkan seseorang betindak dengan penuh kekuasaan terhadap orang yang menyeleweng; 4) sebagai alat protes terhadap ketidakadilan; 5) memberikan kesempatan bagi seseorang melarikan diri untuk sementara waktu dari kehidupan nyata yang membosankan ke dalam dunia khayalan yang indah.

Di pihak lain, Alan Dundes sebagaimana dikutip oleh Sudikan (2014:152) ada beberapa fungsi folklor yang bersifat umum, yaitu (1) membantu pendidikan anak muda, (2) meningkatakan perasaan solidaritas suatu kelompok, (3) memberikan sangsi agar masyarakat 
berperilaku baik atau memberi hukuman, (4) sebagai sarana kritik sosial, (5) memberikan suatu pelarian yang menyenangkan dari kenyataan, (6) mengubah pekerjaan yang membosankan menjadi permainan.

Fungsi sastra lisan yang berbeda dikemukakan oleh Duija (2005:120-121), sastra lisan dalam hal ini pantun Bali, selain sebagai pelipur lara, juga berfungsi sebagai nasihat dan makna filsafat hidup yang berkaitan dengan siklus hidup manusia. Oleh karena itu, pantun Bali dapat berfungsi sebagai ritual estetik sekaligus juga dapat berfungsi sebagai ritual-filosofis.

Mencermati beberapa fungsi sastra lisan yang dikemukakan oleh para pakar folklor, terutama Danandjaja (1994); Duija (2005); Alan Dundes dan Bascom (Sudikan, 2014), dapat ditemukan beberapa fungsi yang lain dalam sastra lisan tanduk bagi masyarakat pendukungnya. Fungsi tersebut meliputi: (1) fungsi dakwah agama Islam di kalangan masyarakat abangan, (2) fungsi solidaritas sosial dan penangkal individualisme, dan (3) sarana pendidikan dalam rangka sosialisasi nilai-nilai. Fungsifungsi tersebut dipegang teguh dan dikembangkan oleh masyarakat Genaharjo sebagai kearifan dan pengetahuan lokal.

\section{Fungsi Dakwah}

Berdasarkan penelitian sastra lisan tanduk, beberapa fungsi yang dikemukakan oleh Alan Dundes sebagaimana dikutip oleh Sudikan (2014:152) dapat diperkaya yaitu dengan menambah satu fungsi berupa fungsi dakwah. Penelitian ini menambah khasanah fungsi folklor, terutama sastra lisan. Fungsi dakwah agama merupakan fungsi yang mendukung fungsi sastra lisan Kentrung Sarabwulan masyarakat Bate Kecamatan Bangilan Kabupaten Tuban. Fungsi dakwah pernah ditemukan oleh Suripan Sadi Hutomo dalam disertasi Cerita Kentrung Sarabwulan (1987). Salah satu fungsi cerita kentrung adalah fungsi dakwah Islam dikalangan masyarakat Islam pedesaan.
Dengan demikian, sastra lisan tanduk mendukung fungsi folklor lisan (baca: sastra lisan) sebagaimana ditemukan dalam penelitian sastra lisan Cerita Kentrung Sarabwulan (Hutomo, 1987:313).

Berdasarkan letak geografisnya, Desa Genaharjo merupakan wilayah pesisir utara Pulau Jawa yang termasuk dalam wilayah Kabupaten Tuban. Meskipun berada di pesisir utara, desa tersebut kental dengan masyarakat pedesaan yang hidup bergantung pada bercocok tanam. Berbeda sekali dengan masyarakat pesisir Tuban yang berada di garis pantai utara. Oleh karena itu, perkembangan masyarakat Genaharjo berbeda dengan masyarakat garis pesisir pantai Tuban. Perbedaan itu tampak dalam ritual budaya, adat kebiasaan, pengetahuan keagamaan, sikap, dan pandangan hidup, termasuk juga sastra lisan tanduk yang berkembang di daerah perbukitan dan pegunungan Tuban.

Selain itu, Kabupaten Tuban merupakan wilayah strategis sejak zaman kerajaan Kahuripan.Pelabuhan Tuban dijadikan pelabuhan internasional dengan membebaskan biaya pajak. Hal ini turut memudahkan penyebaran agama Islam dan agama-agama lain yang masuk di Jawa. Tuban menjadi salah satu pintu gerbang masuknya mubaligh ke tanah Jawa $\left(\right.$ Soeparmo, 1972:54) ${ }^{\mathrm{vi}}$.

Penyebaran agama Islam pun kian pesat, setelah masuknya mubaligh ternama seperti: Sunan Bejagung, Sunan Assamarqandi, Sunan Bonang, dan lain-lain. Penyebaran agama Islam tersebut, lamakelamaan mengalami perubahan, apalagi ketika Sunan Kalijaga ikut andil dalam penyebaran agama Islam di Tuban dan tanah Jawa pada umumnya yang terkenal lentur. Dari uraian tersebut, cara penyebaran agama Islam pun bermacammacam. Penyebaran agama disesuaikan dengan kondisi masyarakat pada saat itu. Begitu juga dengan masyarakat Genaharjo yang memiliki kultur masyarakat pertanian dan kental dengan sebutan masyarakat abangan sampai sekarang. Hal ini, 
mengakibatkan penyebaran agama Islam tidak murni. Penyebaran agama Islam dilakukan melalui kebiasaan masyarakat saat berdoa memohon keselamatan. Berdasarkan hal tersebut, cara penyebaran agama dilakukan dengan memadukan konsep Islam, tetapi tidak menghilangkan kebiasaan masyarakat abangan. Pada saat itulah, tukang tanduk berlomba-lomba untuk menciptakan tanduk berbahasa indah (baca: ngrantik, istilah masyarakat penelitian). Dengan demikian, memasukkan ajaran agama Islam ke tanduk yang digunakan sebagai alat untuk memohon keselamatan, tidak dirasakan bahwa sebenarnya tanduk diciptakan dan dikembangkan untuk dakwah agama Islam di kalangan masyarakat pedesaan.
Berdasarkan uraian tersebut, sastra lisan tanduk memiliki fungsi sebagai alat dakwah oleh tukang tanduk kepada masyarakat Genaharjo. Dengan demikian, tukang tanduk adalah mubaligh (pedakwah) simbolik. Sastra lisan tanduk dijadikan media dakwah di kalangan masyarakat abangan. Hal ini dapat dibuktikan, bahwa dalam tanduk diselipi ketahuhidan, pengenalan nama-nama nabi terutama nur Nabi Muhammad beserta suri tauladannya, dan para penyebar agama di tanah Jawa, terutama Sunan Kalijaga dan Sunan Giri yang dipadukan dengan beberapa tokoh dan simbol binatang-dimaksudkan untuk menyamarkan ajaran.

\section{Tanduk. Ngedekake Griya}

...

Kula meningani selamet Kanjeng Sunan Kali Jaga ingkang jagi saka sekawan saperabote

...

Wonten malib Sekul Buket punika meningani slamet Nabi Adam

Wonten malih Rujak Legi meningani slamet Nabi Mustaka

Wonten malih jajan pasar meningani slamet Dangpo Awang lan Sungging Kara

Wonten malih bubur abang punika meningani selamet Nabi Ibrabim

Wonten malib bubur tulak punika meningani slamet para nabi

Wonten sengkala maya-maya saking wetan rupa kuning tinulak nabi Adam bangsul mengetan

Dene wonten sengkala saking kidul kang abrit rupane tinulak nabi Ibrahim saking lor bangsul ngidul

Dene wonten sangkala maya-maya saking kulon cemeng rupane tinulak. Nabi Sulaiman saking wetan bangsul mengilen

Dene wonten sengkala saking lor werna pethak tinulak. Nabi Mubammad saking kidul bangsul ngalor

Wonten sangkala saking inggil kang biru rupane tinulak nabi Panutup saking ngandap bangsul menginggil

Dene wonten sangkala saking ngandap warna kembang terong tinulak Siti

Fatimah saking inggil bangsul mengandap

Sedaya dipun aturi kurmat mugi Allah paring ijabah pandongane

Kula sununaken kurmat selamet Bapa Biyang paring sandang kalawan tedan rinten kelawan dalu nerusaken, bumi, toya, api, lan tosan

...

(Tanduk Ngedekake Griya, data lengkap ada pada penulis)

Penggunaan beberapa istilah ketauhidan secara simbolik dan pemakaian nama-nama tokoh tersebut menunjukkan bahwa sastra lisan tanduk memiliki fungsi sebagai alat dakwah di kalangan masyarakat Islam pedesaan yang masih kental dengan abangan. 
Penggunaan nama tokoh-tokoh dengan simbol arah dan warna merupakan ajaran yang sengaja disamarkan. Begitu juga dengan istilah Bapa Biyang yang sebenarnya adalah istilah untuk menyebut Tuhan yang sengaja disembunyikan, agar tidak terjadi gejolak di masyarakat pada saat itu. Dengan demikian dapat dipahami, bahwa fungsi sastra lisan tanduk tidak semata-mata sebagai hiburan seperti halnya fungsi sastra lisan pada umumnya yang dikemukakan oleh Amir (2013:34), bahwa fungsi utama sastra lisan adalah untuk hiburan. Sastra lisan tanduk memiliki kekontrasan fungsi sebagaimana pendapat tersebut. Sastra lisan yang berkembang pada masyarakat Genaharjo lebih mengarah ke fungsi kesakralan di tengah masyarakat. Kesakralan dalam keagamaan tersebut mengarah pada sikap religiusitas masyarakat dalam menjalani kehidupan kolektif dalam bermasyarakat.

\section{Fungsi Solidaritas Sosial}

Masyarakat Genaharjo sebagai masyarakat kolektif, pendukung sastra lisan tanduk semakin diperkokoh dengan adanya slametan. Solidaritas masyarakat Genaharjo semakin dipertebal dengan adanya beberapa slametan daur hidup, seperti: slametan gegriyan, brokoban, mantu, sunatan, dan lainlain. Siapa pun yang datang dalam slametan selalu menunjukkan solidaritasnya yaitu solidaritas sekata, seucap, dan segerakan (kepala, tangan, dan bibir). Ucapan pendukung hajat yaitu nggih. Dengan mengucapkan kata itu, berarti antara pemilik hajat, penampil (tukang tanduk), dan saksi (tetangga yang hadir dalam kenduren) menyatakan sepaham dan setuju bahwa ada hajat yang harus diaminkan.

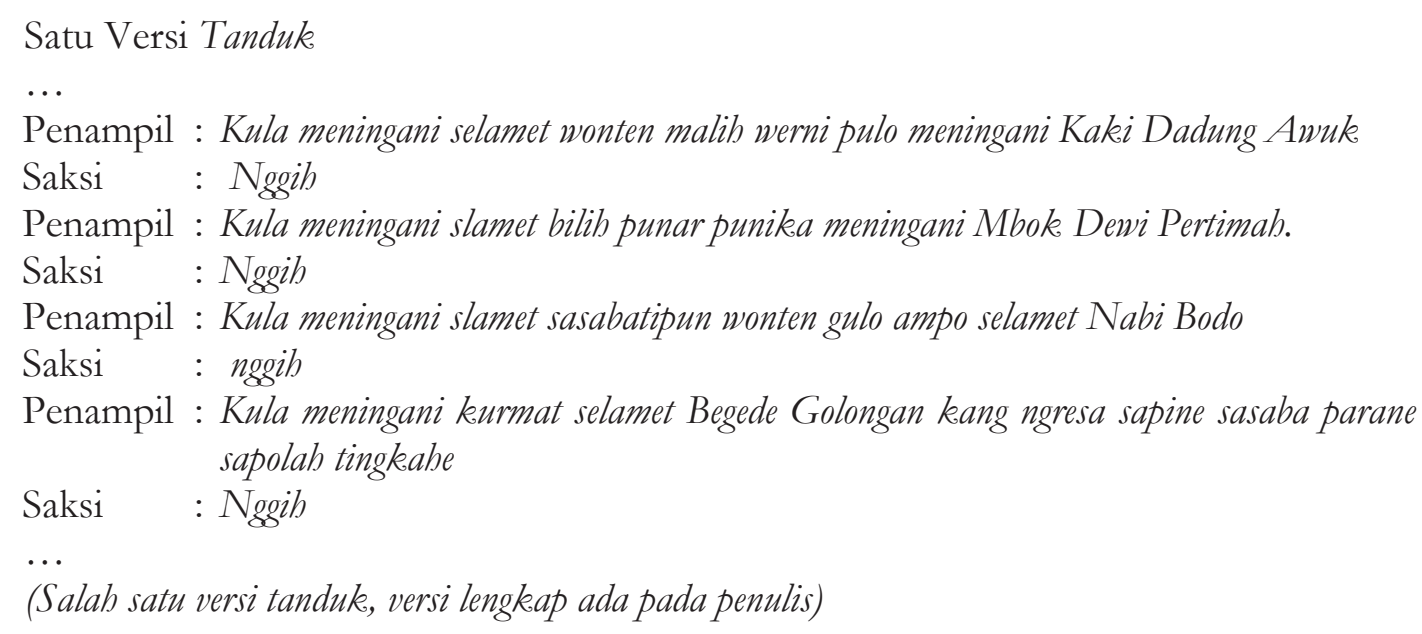

Apabila salah satu wakil keluarga tetangga tidak hadir, biasanya wakil dari keluarga lain yang berdekatan dengan tetangga yang tidak hadir tersebut untuk selalu membawakan berkat (nasi yang dibungkus daun jati) untuk diberikan kepada keluarga yang tidak hadir. Apabila tidak ada yang dititipi berkat tersebut, pemilik hajat rela mengantarkan sampai di rumah tetangga yang tidak hadir dalam kenduren. Fenomena semacam ini dinamakan mider berkat. Pengamatan di lapangan yang menunjukkan peristiwa semacam ini, dapat diketahui bahwa solidaritas yang ada dalam ucapan dan tindakan individu dalam masyarakat harus dilaksanakan, sebagaimana suara pengimbuh nggih ketika menjawab ikrar tukang tanduk.

Sebagaimana dikemukakan oleh Atmosuwito (2010:123); Mangunwijaya (1992:12), mengatakan bahwa solidaritas terjadi apabila ada ikatan atau pengikatan diri, kemudian menyerahkan diri, tunduk, dan taat dalam pengertian positif, dikaitakan dengan kebahagiaan yang penuh kemuliaan. Pengikatan tersebut yang 
dinamakan perasaan religius. Pendapat tersebut menguatkan bahwa fungsi religius dalam sastra lisan tanduk mampu mengikat personal dalam ikatan kolektif. Ikatan tersebut memantapkan solidaritas antarindividu dalam masyarakat.

Masyarakat Genaharjo memandang bahwa penampilan sastra lisan tanduk mampu menggetarkan nurani personal untuk bersatu membentuk paguyuban. Paguyuban ini terbentuk dari ikatan solidaritas. Menurut Soekanto (2012:116), hal semacam ini dikenal dengan istilah gemeinschaft pertama kali dikemukakan oleh Ferdinand Tonnies. Paguyuban merupakan bentuk kehidupan bersama di mana anggotanya diikat oleh hubungan batin yang bersifat alamiah. Dengan demikian, masyarakat Genaharjo membentuk sebuah paguyuban (gemeinschaft) melalui sastra lisan tanduk.

Nurani dan rasa kemanusiaan untuk hadir di tengah tradisi kepungan yang memanfaatkan sastra lisan Tanduk, menunjukkan bahwa eksistensi sebagai makhluk sosial tidak dapat dilepaskan begitu saja. Kehadiran para tetangga yang diundang membuktikan bahwa rasa religiusitas masyarakat begitu kuat. Perasaan demikian, Soekanto (2012:133), menamakan perasaan komuniti (communitysentiment) yang diwujudkan untuk membentuk suatu masyarakat.

Sastra lisan tanduk mampu mengikis individualisme dan memupuk ikatan sosial merupakan fungsi yang lain dalam sastra lisan tanduk. Intensitas represi individualisme masyarakat perkotaan yang berangsur-angsur memyusup ke masyarakat Genaharjo karena pengaruh gaya hidup perkotaan, dapat ditangkal menggunakan sastra lisan tanduk. Kenduren yang berkala dalam seluruh keluarga mampu mengikis individualisme.Dengan adanya undangan untuk menjadi saksi tukang tanduk mengikrarkan hajat seseorang, perasaan individuaisme tergerus.Sikap tolongmenolong dan gotong-royong semakin dipertebal bagi masyarakat pendukung sastra lisan tanduk. Dengan demikian, sastra lisan tanduk mampu mengikat solidaritas masyarakat yang tercermin pada saat kepungan berlangsung.

\section{Sarana Pendidikan dalam Rangka Sosialisasi Nilai-Nilai}

Sastra lisan tanduk dapat menjadi sarana untuk menyampaikan pesan kearifan. Khalayak yang hadir dalam penampilan sastra lisan tanduk, terjadi saling memberikan dan menerima informasi. Terjadi proses pendidikan: kaum tua terutama tukang tanduk memberikan pengarahan kepada anggota masyarakat yang ikut hadir dalam rangka memaknai hidup bermasyarakat. Tukang tanduk bercerita masalah-masalah yang sedang hangat di sekitar desa sebelum memulai kenduren dan memberikan cara yang arif dalam menyelesaikan masalah tersebut. Suatu misal, ketika terjadi serangan tikus di sawah. Tukang tanduk memberikan pengarahan agar tikus-tikus tersebut tidak dibunuh, tetapi diberikan makan secukupnya berupa ikan asin, walur (sejenis tumbuhan pagar), dan lontong. Contoh tersebut merupakan penyampaian nilai-nilai sosial terhadap sesama manusia untuk menjaga keseimbangan alam melalui pendidikan simbolik.

Nilai-nilai yang dibangun oleh masyarakat bukan sebatas antarmanusia saja, melainkan nilai sosial antarmanusia dalam masyarakat harus disejajarkan dengan interaksi kepada binatang, tumbuhan, dan alam semesta. Hal ini terjadi sebagaimana masyarakat setempat memberikan doa keselamatan kepada rajabutamale melalui Tanduk kupatan sapi.

Tanduk kupatan sapi merupakan tanduk yang digunakan untuk keselamatan dan kemuliaan sapi dan sejenisnya sebagai raja kekayaan bagi masyarakat desa, selain hasil bumi. Kekayaan berupa rajabutamale perlu dimohonkan keselamatan, agar diberikan kelancaran apabila diajak membajak pada musim pra-tanam berikutnya. 


\begin{abstract}
Kula meningani selamet wonten malih werni pulo meningani Kaki Dadung Awnk, nggih
Kula meningani slamet bilih punar punika meningani Mbok Dewi Pertimah, nggih

kula meningani slamet sasabatipun wonten gulo ampo selamet Nabi Bodo, nggih

Kula meningani kurmat selamet Begede Golongan kang ngresa sapine sasaba parane sapolah tingkahe, nggih

‥

(saya menghormati keselamatan di dalamnya ada juga pulo untuk menghormati Kaki Dadung Awuk, ya

Saya menghormati keselamatan kalau punar itu untuk menghormati Mbok Dewi Pertimah, ya

Saya menghormati keselamatan sahabat (sapi) yang berupa gula ampo menghormati Nabi Bodo, ya

Saya mengormati keselamatan Begede Golongan yang menjaga sapi dan arah kepergiannya dan seluruh tingkah lakunya, ya)

(Tanduk Kupatan Sapi, data lengkap ada pada penulis)
\end{abstract}

Keselamatan juga ditujukan kepada tumbuhan pangan seperti padi dan jagung, seperti dalam tanduk unduh-unduh, keleman, dan wimit. Dengan demikian, manusia harus

selalu menjaga nilai-nilai yang dibangun masyarakat secara turun-temurun mengenai pengakuan binatang rajabutamale dan tumbuhan pangan.

\title{
Podo ngedalaken ambeng sekul asrep saprabote punika badhe \\ nyelameti Mbok Sri Penganti lan Mbok Sri Sedana \\ Ingkang gumelar ing siti wiyar, ingkang riyek, ingkang rempel sampun ngantos wonten ingkang kantun \\ (Bapak Podo mengeluarkan nasi uduk sebagai tumpeng dan perabotnya untuk memohon keselamatan Mbok Sri Penganti dan Mbok Sri Sedana \\ Yang masih berada di lahan luas, yang rusak, yang jatuh, tidak ada yang tertinggal) \\ (Tanduk Wiwit, data lengkap ada pada penulis)
}

Tanduk Wiwit merupakan tanduk yang ditampilkan ketika hendak memetik padi, jagung, atau seluruh tanaman pangan di lahan.Tanduk ini berisi permohonan keselamatan tumbuhan yang siap dipanen kepada Pencipta.Tujuan tanduk ini ditampilkan adalah memohon keselamatan bagi tumbuhan (padi, jagung, kacang, dll), binatang (sapi, kerbau, kambing), dan manusia sendiri.Sebagaimana ajaran pendidikan akhlak, dalam masyarakat penelitian, mendoakan keselamatan tidak hanya pada diri sendiri dan manusia sebagai tolok ukur interaksi masyarakat, melainkan juga mendoakan keselamatan hewan dan tumbuhan sebagai bagian dari alam semesta selain manusia.

Masyarakat Genaharjo selaku pendukung sastra lisan tanduk mengajarkan cara memuliakan tamu hajatan atau kenduren. Khalayak yang hadir dalam kenduren, merupakan tamu yang harus dihormati. Hal ini dilakukan dengan cara penyapaan yang halus ketika memasuki pintu rumah, disilakan duduk, dan tidak lupa biasanya disediakan kopi dan rokok. Memuliakan tamu merupakan hal yang wajib dilaksanakan oleh masyarakat setempat, agar tamu yang hadir tidak sekadar hadir dan duduk.Akan tetapi ikut berperan dalam menyaksikan hajat yang 
dimaksudkan sesuai dengan keinginan pemilik hajat.Peristiwa semacam ini adalah salah satu nilai yang disosialisasikan melalui pendidikan dalam kehidupan masyarakat.

Sebagaimana nilai yang
dimaksudkan, bahwa nilai yang dibangun masyarakat melalui pendidikan-pendidikan yang tersembunyi dibalik pemikiran masyarakat, selalu diterapkan dalam penanaman etika dan sopan santun. Tata cara pengajaran dan pendidikan oleh tukang tanduk kepada masyarakat melalui media sastra lisan diharapkan agar masyarakat tidak merasa digurui atau dikatakan masyarakat kelas rendah yang tidak berperadaban. Dengan demikian, keharmonisan kehidupan antarindividu dalam masyarakat tidak tumpang tindih antara masyarakat pasif dan masyarakat aktif berperan dalam masyarakat setempat.

Berdasarkan pemaparan tersebut, dapat ditemukan bahwa sastra lisan tanduk dan masyarakat Genaharjo dalam kehidupan masyarakat setempat, ada sistem nilai yang dibangun.Sistem nilai yang ada menjadi pilihan hidup kolektif. Pilihan cara hidup tersebut secara kolektif dilakukan oleh masyarakat Genaharjo untuk bertindak dan berperilaku lebih maju. Nilai yang menjadi pilihan dibangun masyarakat adalah nilai apa yang baik dan berharga untuk membangun masyarakat berkemajuan (Sanusi, 2015: 28).

Menurut Keeney, sebagaimana dikutip Sanusi (2015:64) bahwa nilai dijadikan dasar untuk semua yang dilakukan manusia. Dengan demikian, masyarakat Genaharjo melalui sastra lisan tanduk secara sadar telah membangun nilai untuk menjaga harmoni dengan alam, hubungan mikrokosmosis sesama manusia, dan hubungan makrokosmosis kepada Sang Pencipta. Nilai tersebut menjadi nilai yang sangat diutamakan. Dengan demikian, berkembanglah kearifan lokal untuk mengenal istilah keagamaan, tokoh simbolik, tumbuhan, musim, arah mata angin, dan binatang yang bertujuan memelihara keharmonisan melalui sastra lisan tanduk.

Fungsi sastra lisan tanduk, tampaknya agak berbeda dengan fungsi nyanyian rakyat Bugis. Amaluddin (2010:61) menemukan beberapa fungsi dalam nyanyian rakyat Bugis yaitu: (1) digunakan sebagai sarana protes/kritik sosial, (2) sebagai pengawas norma-norma yang berlaku dalam masyarakat (sebagai fungsi adat), dan (3) sebagai sarana pendidikan bagi generasi muda Bugis. Dari perbedaan tersebut, dapat dipahami bahwa setiap sastra lisan, baik yang dibacakan atau dinyanyikan untuk dipertunjukkan di depan khalayak, memiliki fungsi yang berbedabeda dalam setiap penampilannya.

\section{SIMPULAN}

Hasil penelitian menunjukkan bahwa sastra lisan tanduk memiliki sejumlah fungsi yaitu 1) sebagai media dakwah dikalangan masyarakat pedesaan, 2) sebagai alat pemupuk solidaritas sosia dan penangkal individualisme. Fungsi semacam ini merupakan sikap dan pandangan hidup masyarakat Jawa di Tuban dan masyarakat Genaharjo pada khususnya yang senantiasa mendambakan, kebersamaan, keselamatan, dan keseimbangan hidup, dan 3) sebagai sarana pendidikan dalam rangka sosialisasi nilai-nilai. Konsep nilai yang dibangun adalah bagaimana memaknai kehidupan bersama dalam masyarakat. Beberapa fungsi tersebut mengacu pada suatu tujuan bahwa pada hakikatnya manusia hidup harus selalu menjaga keseimbangan, keselarasan, kebersamaan, dan kesepahaman untuk membangun iklim masyarakat yang aman, nyaman, dan berkemajuan.

Berdasarkan simpulan tersebut, rekomendasi yang mendesak yang perlu dilakukan peneliti berikutnya adalah penelitian sastra lisan tanduk dikaitkan dengan wacana kultural. Bagaimanapun juga, sastra lisan tanduk adalah salah satu produk wacana lisan yang berkembang di masyarakat Genaharjo. Selain itu, penelitian yang lebih mendalam mengenai sastra lisan 
tanduk untuk mengetahui asalnya dan keterkaitan dengan genre sastra lisan lain, serta sejauh mana pengaruh Islam terhadap keberadaan sastra lisan tersebut.

\section{DAFTAR RUJUKAN}

Amaluddin. (2010). Kajian Bentuk, Fungsi, Nilai, dan Strategi Pelestariannya. Jurnal Bahasa dan Seni Universitas Negeri Malang, tahun 38 nomor 1, Februari 2010.

Amir, A. (2013). Sastra Lisan Indonesia. Yogyakarta: Penerbit Andi.

Atmosuwito, S. (2010). Peribal Sastra dan Religiusitas dalam Sastra. Bandung: Sinar Baru Algesindo.

Bungin, B. (2003). Penelitian Kualitatif. Jakarta:Kencana

Danandjaja, J. (1994). Folklor Indonesia: Ilmu Gosip, Dongeng, dan Lain-lain. Jakarta: Pustaka Utama Grafiti.

Duija, I.N. (2005). Tradisi Lisan, Naskah, dan Sejarab: Sebuah Catatan Politik. Kebudayaan. Wacana: Jurnal Ilmu Pengetahuan Budaya Universitas Indonesia, volume 07 nomor 02, Oktober 2005.

Endraswara, S. (2006). Metodologi Penelitian Kebudayaan. Yogyakarta: Gadjah Mada University Press.

Hutomo, S.S. (1987). Cerita Kentrung Sarahwulan di Tuban. Disertasi. Jakarta: Universitas Indonesia.

Luxemburg, et al. (1992). Pengantar Ilmu Sastra. Diterjemahkan oleh Dick Hartoko. Jakarta: Gramedia Pustaka Utama.
Mangunwijaya, Y.B. (1992). Sastra dan Religiusitas. Yogyakarta: Kanisius.

Prastowo, Andi. (2010). Menguasai Teknikteknik Koleksi Data Penelitian Kualitatif. Yogyakarta: Diva Press.

Ratna, N.K. (2010). Metodologi Penelitian Kajian Budaya dan Ilmu Sosial Humaniora pada Umumnya.Yogyakarta: Pustaka Pelajar.

Sanusi, A. (2015). Sistem Nilai Alternatif Wajah-Wajah Pendidikan. Bandung: Nuansa Cendekia.

Soekanto, S. (2012). Sosiologi Suatu Pengantar. Jakarta: Rajawali Pers.

Soeparmo, R. (1972). Tjatatan Sedjarah 700 Tabun Tuban. Tuban: Sruni.

Spradley, J.P.(1997). Metode Etnografi. (diterjemahkan oleh Misbah Zulfa Elizabeth). Yogyakarta: Tiara Wacana.

Sudikan, S.Y.(2001). Metode Penelitian Kebudayaan. Surabaya: Citra Wacana.

Sudikan, S.Y. (2014). Metode Penelitian Sastra Lisan. Lamongan: Pustaka Ilalang Group.

\section{UCAPAN TERIMA KASIH}

Peneliti mengucapkan terima kasih kepada berbagai pihak yang telah membantu dalam pelaksanaan penelitian ini. ucapan terima kasih disampaikan kepada Dewan Redaksi Jurnal Pendidikan Babasa dan Sastra yang telah mereviu dan memublikasikan artikel hasil penelitian ini. 


\section{CATATAN :}

iTanduk adalah sastra lisan yang digunakan sebagai pengantar doa keselamatan pada saat kenduren yang berkaitan dengan daur hidup manusia.

ii Tradisi silaturahim ke rumah sanak saudara dengan membawa makanan dan jajanan tradisional. iiiJames P. Spradley mengajukan beberapa syarat dalam penentuan informan penelitian. Hal yang terpenting adalah informan pertama yang dipilih haruslah memenuhi lima persyaratan (Spradley, 2007:68).

iv Sudikan dalam buku Metode Penelitian Kebudayaan, seorang informan dipilih yang paling memahami objek yang diteliti atau dengan kata lain, seorang informan harus paham budaya aslinya (Sudikan, 2001:91)

'Teori fungsi dipelopori oleh para ahli folklor, di antaranya William R. Bascom, Alan Dundes, dan Ruth Finnegan.Masing-masing ahli memiliki pandangan yang berbeda, karena landasan filosofis, daya pengamatan, dan daya imajinasinya berbeda (Sudikan, 2014:151).

viBerdasarkan catatan catatan Ying Yai Sheng Lan yang dikumpulkan oleh (Soeparmo, 1972:54), bahwa sebelum orang-orang Cina ke Majapahit, lebih dulu singgah di Tuban. Hal ini mengakibatkan Tuban menjadi wilayah yang ramai hingga Islam masuk ke Tuban. 